"This document is the Accepted Manuscript version of a Published Work that appeared in final form in Journal of the American Chemical Society, copyright (C) American Chemical Society after peer review and technical editing by the publisher. To access the final edited and published work see [insert ACS Articles on Request authordirected link to Published Work, see https://pubs.acs.org/doi/pdf/10.1021/jacs.6b10351

\title{
Alkyl Bromides as Mild Hydride Sources in Ni-Catalyzed Hydroam- idation of Alkynes with Isocyanates
}

\author{
Xueqiang Wang, ${ }^{\dagger}$ Masaki Nakajima, ${ }^{\dagger \dagger}$ Eloisa Serrano ${ }^{\dagger \dagger}$ and Ruben Martin ${ }^{\dagger{ }^{\prime} *}$ \\ $\dagger$ Institute of Chemical Research of Catalonia (ICIQ), The Barcelona Institute of Science and Technology, Av. Països Cata- \\ lans 16, 43007 Tarragona, Spain
}

$\S$ ICREA, Passeig Lluïs Companys, 23, 08010, Barcelona, Spain

Supporting Information Placeholder

ABSTRACT: A catalytic hydroamidation of alkynes with isocyanates using alkyl bromides as hydride sources has been developed. The method turns parasitic $\beta$-hydride elimination into a strategic advantage, rapidly affording acrylamides with excellent chemo- and regioselectivity.

Hydrometalation of alkynes ranks among the most fundamental reactions in organometallic chemistry, enabling a rapid access to well-defined alkenyl metal species. ${ }^{1}$ At present, intermolecular $\mathrm{C}-\mathrm{C}$ bond-forming reactions via catalytic hydrofunctionalization of alkynes remains confined to the utilization of well-defined metal hydride species or the presence of acids as hydrogen donors (Scheme 1, path a). ${ }^{1,2}$ Unfortunately, these conditions preclude the use of partners sensitive to either metal hydrides or acidic media. If successful, a new design principle capable of expanding the boundaries of alkyne hydrofunctionalization for $\mathrm{C}-\mathrm{C}$ bond-formation by using unconventional hydride sources could lead to new knowledge in our ever-growing organometallic arsenal.

Scheme 1. Alkyne Hydrofunctionalization and Isocyanates.

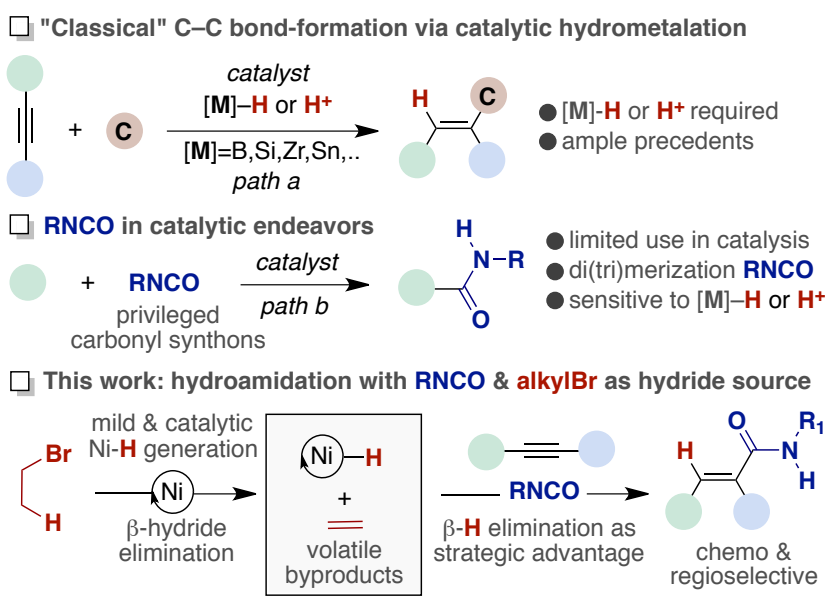

Prompted by the utmost synthetic relevance of acrylamides in pharmaceuticals, agrochemicals and polymers, ${ }^{3}$ we wondered whether it would be possible to design a catalytic hydroamidation of alkynes by intercepting the in situ generated alkenyl metal species with isocyanates, privileged synthons in both industrial and academic laboratories. ${ }^{4,5}$ At the outset of our investigations, however, it was unclear whether such protocol could ever be implemented, as isocyanates have rarely been employed in catalytic endeavors other than cycloaddition events (Scheme 1, path b). ${ }^{6,7}$ This is likely due to their exceptional sensitivity to both hydrides and proton sources as well as their strong binding properties to low valent metal species. ${ }^{8,9}$ We anticipated that a mild generation of the transient metal hydride would be critical for success. ${ }^{10}$ To such end, we questioned whether we could turn $\beta$-hydride elimination, traditionally considered a drawback when coupling unactivated alkyl halides, ${ }^{11}$ into a strategic advantage, thus offering a novel method capable of delivering metal hydrides under mild conditions while releasing volatile byproducts (Scheme 1, bottom). ${ }^{12}$ As part of our interest in heterocumulenes, ${ }^{13,7 \mathrm{a}-\mathrm{b}}$ we report herein the successful realization of this new design principle, accessing a wide range of acrylamides in a both chemo- and regioselective manner.

Table 1. Optimization of the Reaction Conditions. ${ }^{a}$ 


\begin{tabular}{|c|c|c|c|c|}
\hline \multirow{3}{*}{\multicolumn{2}{|c|}{$\begin{array}{c}\mathrm{Ph} \frac{\overline{\overline{1 a}}}{\overline{1 a}} \mathrm{Ph} \\
+ \\
t \text {-BuNCO (2a) }\end{array}$}} & \multirow{3}{*}{\multicolumn{2}{|c|}{$\begin{array}{c}\mathrm{NiBr}_{2} \cdot \text { diglyme }(10 \mathrm{~mol} \%) \\
\text { L4 (20 mol \%) } \\
\mathrm{Mn}, \boldsymbol{i}-\mathrm{PrBr}(1.50 \text { equiv }) \\
\mathrm{NMP}, \mathrm{rt}\end{array}$}} & \multirow[t]{3}{*}{ O } \\
\hline & & & & \\
\hline & & & & \\
\hline Entry & Deviation fron & tandard conditions & $2 \mathbf{a}(\%)^{b}$ & \\
\hline 1 & None & & $91^{c}\left(83^{d}\right)$ & \\
\hline 2 & L1 instead of I & & 0 & \\
\hline 3 & L2 instead of $\mathbf{L}$ & & 45 & \\
\hline 4 & L3 instead of $\mathbf{L}$ & & 0 & 1 \\
\hline 5 & L5 instead of I & & 64 & $\mathrm{R}=\mathrm{Me}(\mathrm{L} 2)$ \\
\hline 6 & L6 instead of I & & 66 & \\
\hline 7 & $\mathrm{PPh}_{3}$ instead & & 38 & $3^{2}$ \\
\hline 8 & $\mathrm{Ni}(\mathrm{COD})_{2}$ as c & alyst & 68 & \\
\hline 9 & $t$-BuBr as hydr & source & 69 & \\
\hline 10 & DMF (DMA) in & ad of NMP & $73(54)$ & $\mathrm{R}^{1}$ \\
\hline 11 & Zn instead of I & & 54 & \\
\hline 12 & $\mathrm{Me}(\mathrm{EtO})_{2} \mathrm{SiH}$ & ) as hydride source & $17^{e}(0)$ & $\mathrm{R}^{1}=\mathrm{M}$ \\
\hline 13 & $\mathrm{NaBH}_{4}(t-\mathrm{BuO}$ & s hydride source & $0(0)$ & $\mathrm{R}^{1}=n-\mathrm{Bu} ; \mathrm{R}^{2}=\mathrm{Ph}(\mathbf{L} 5)$ \\
\hline 14 & No $\mathrm{NiBr}_{2} \cdot$ digly & no $\mathbf{L} 5$ or no $\mathrm{Mn}$ & 0 & $\mathrm{R}^{1}=n-\mathrm{Bu} ; \mathrm{R}^{2}=\mathrm{Me}(\mathrm{L} \mathbf{6})$ \\
\hline
\end{tabular}

${ }^{a} \mathbf{1 a}(0.25 \mathrm{mmol}), \mathbf{2 a}(0.38 \mathrm{mmol}), \mathrm{NiBr}_{2} \cdot$ diglyme (10 $\mathrm{mol} \%)$, L4 (20 mol\%), Mn (0.38 mmol), NMP (0.25 M) at $\mathrm{rt}, 12$ h. ${ }^{b}$ HPLC yields using naphthalene as internal standard. ${ }^{c}$ Isolated yield. ${ }^{d} \mathrm{NiBr}_{2}$-diglyme (5 mol\%), $24 \mathrm{~h} .{ }^{e}$ $\mathrm{Na}_{2} \mathrm{CO}_{3}(0.75 \mathrm{mmol})$, no $\mathrm{Mn}, E: Z=5: 1$.

We started our proposed protocol by evaluating the hydroamidation of $\mathbf{1 a}$ with $\mathbf{2 a}$ (Table 1), as the $t$-butyl group in acrylamides could be used as a vehicle for further functionalization. ${ }^{14}$ After careful optimization, ${ }^{15}$ we found that a combination of $\mathrm{NiBr}_{2}$.diglyme, $\mathbf{L 4}, \mathrm{Mn}$ as reducing agent in NMP at $\mathrm{rt}$, and using simple $i$ - $\mathrm{PrBr}$ as the hydride source provided the best results, resulting in $91 \%$ isolated yield of $\mathbf{3 a}$ as a single diastereoisomer (entry 1). In line with our expectations, subtle modifications on the ligand backbone led to profound changes on the reaction outcome, with ortho-substituted 1,10phenanthroline ligands being considerably more reactive than bipyridine motifs (entries 2-6), suggesting that a reasonable steric bulk was critical for stabilizing the transient reaction species. Likewise, other Ni sources, solvents, reducing agents, or related alkyl bromides as hydride sources resulted in lower yields (entries 7-11). ${ }^{15}$ As expected, classical hydrometalation techniques based on $\mathrm{R}_{3} \mathrm{SiH}, \mathrm{H}_{2}, \mathrm{NaBH}_{4}$ or alcohols as protic sources resulted in the degradation of $\mathbf{2 a}$, with little of $\mathbf{3} \mathbf{a}$, if any, being observed in the crude mixtures (entries 12-13). Notably, only traces of a reductive amidation of $i-\mathrm{PrBr}$ were observed, thus showing the unique features of our method. ${ }^{7 \mathrm{a}}$ Control experiments in the absence of $\mathrm{Ni}$ catalyst, $\mathbf{L 4}, i-\mathrm{PrBr}$ or $\mathrm{Mn}$ revealed that all these parameters were necessary for the reaction to occur (entry 14).

Table 2. Scope of Aryl- \& Alkyl-Substituted Acetylenes. ${ }^{a, b}$

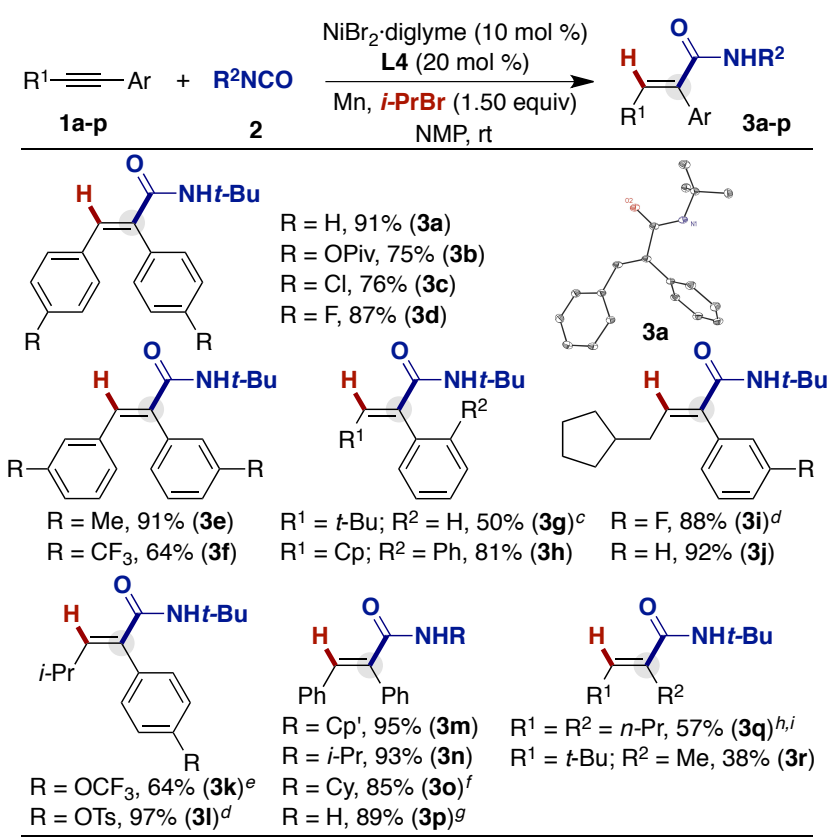

${ }^{a}$ As Table 1 (entry 1), at $0.50 \mathrm{mmol} \mathrm{scale.}{ }^{b}$ Isolated yields, average of at least two independent runs. ${ }^{c} 35^{\circ} \mathrm{C}, 72 \mathrm{~h} .{ }^{d} E / Z$ $=14: 1 .{ }^{e} E / Z=15: 1{ }^{f} E / Z=13: 1{ }^{g}$ Subsequent TFA treatment at reflux. ${ }^{h}$ Using neocuproine $(20 \mathrm{~mol} \%)$ as ligand at $10{ }^{\circ} \mathrm{C} .{ }^{i} E / Z=6: 1 . \mathrm{Cp}=$ cyclopropyl, Cp' = cyclopentyl.

With an optimized set of conditions in hand, we turned our attention to validate the generality of our hydroamidation protocol. As illustrated in Table 2, a host of different alkyl- or aryl-substituted symmetrical or unsymmetrical acetylenes could participate well in the targeted reaction. ${ }^{16}$ Notably, similar results were obtained regardless of the electronic and steric parameters of the substituents on the alkyne terminus. In all cases, a single regioisomer with high levels of diastereoselectivity was obtained, with the amide function located adjacent to the aromatic motif, an observation corroborated by X-ray crystallography $(\mathbf{3 a}, \mathbf{3 l}){ }^{15}$ Particularly interesting was the ability to accommodate aryl halides $(\mathbf{3 c}, \mathbf{3 d}, \mathbf{3 i})$, pivalates $(\mathbf{3 b})$ or tosylates (3l), as these motifs have successfully been used as counterparts in Ni-catalyzed cross-coupling reactions, ${ }^{17}$ thus providing an additional handle for further derivatization. Notably, the coupling of isocyanates other than 2a posed no problems, and 3m-3o could all be prepared in high yields. Upon simple exposure to TFA, ${ }^{15}$ we found that primary amides could be within reach (3p), thus effectively using the $t$-butyl group as a masked form of hydrogen while leading to $a$ priori inaccessible building blocks via classical alkyne hydroamidation processes. ${ }^{1,5}$ Importantly, the hydroamidation could also be applied to aliphatic internal alkynes $(\mathbf{3 q}, \mathbf{3 r})$, albeit in slightly lower yields.

Table 3. Scope of Silyl- \& Boryl-Substituted Acetylenes. ${ }^{a, b}$ 


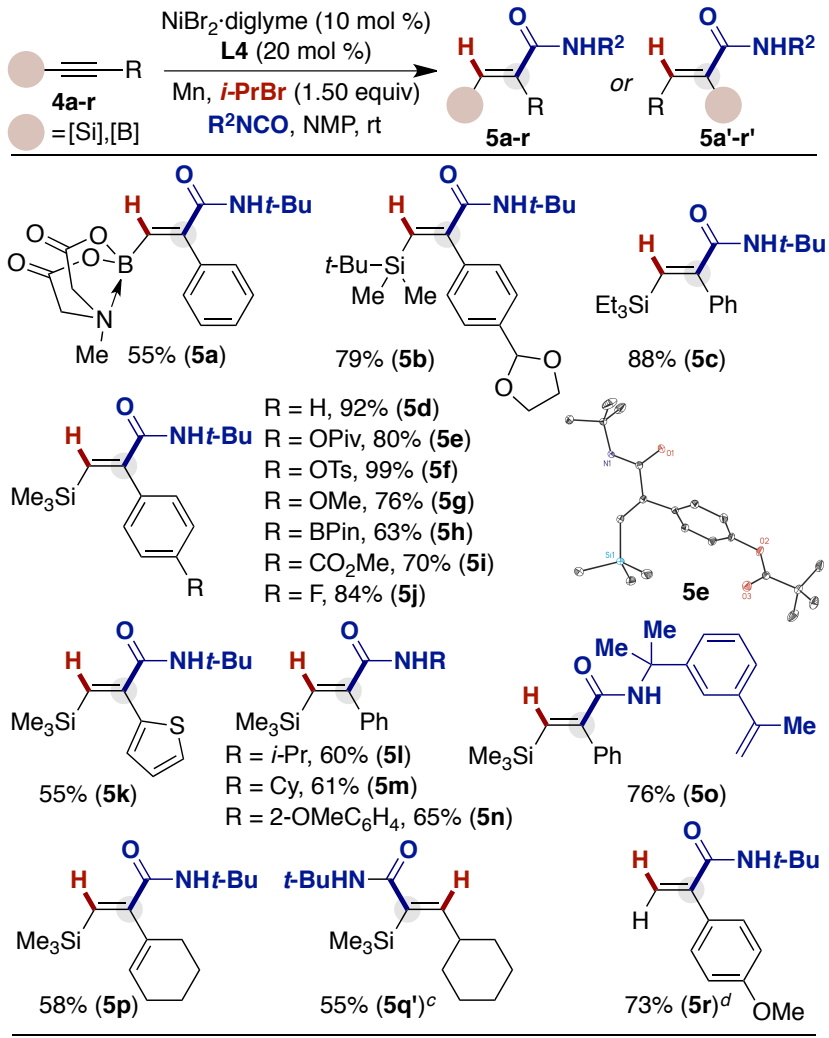

${ }^{a}$ As Table 1 (entry 1), at $0.50 \mathrm{mmol} \mathrm{scale.}{ }^{b}$ Isolated yields, average of two independent runs. ${ }^{c} E / Z=1.8: 1 .{ }^{d}$ Using $\mathbf{1 r}$ followed by TBAF (1.20 equiv).

Encouraged by these results, we questioned whether we could extend the scope of our protocol to silyl- or borylsubstituted acetylenes, as these motifs have shown to be versatile intermediates in organic synthesis. ${ }^{18}$ As shown in Table 3, this turned out to be the case. As for the results compiled in Table 2, the amide function in $\mathbf{5 a - 5 p}$ was invariably located adjacent to the aromatic or vinylic motif, an assumption that was confirmed by Xray crystallography (5e). The absence of a $\pi$-component on the alkyne terminus resulted in $\mathbf{5 q}$ ', a selectivity switch that is attributed to the electropositivity of Si and hyperconjugation into the adjacent $\mathrm{Si}-\mathrm{C} \sigma^{*}$ orbital. ${ }^{19} \mathrm{As}$ shown for $\mathbf{5 n}$, the reaction could be extended to aromatic isocyanates with similar ease. Interestingly, desilylation with TBAF yielded $\mathbf{5 r}$, thus accessing compounds that formally derive from a hydroamidation of free alkynes. As anticipated, the chemoselectivity posed no problems, as acetals (5b), esters (5i), aryl boronates $(\mathbf{5 h})$, heteroaromatics $(\mathbf{5 k})$, aryl fluorides $(\mathbf{5 j})$ or alkenes $(\mathbf{5 0}$, 5p) could perfectly be tolerated. As for Table 2, groups amenable for Ni-catalyzed $\mathrm{C}-\mathrm{O}$ cleavage such as aryl pivalates (5e) or tosylates (5f) did not compete with the efficacy of our hydroamidation event. ${ }^{20}$ The usefulness of our synthetic method is illustrated in Scheme 2, by rapidly preparing synthetically relevant $\mathbf{7}$ and $\mathbf{8}$ in high yields by a $\mathrm{N}$-alkylation/ipso-halogenation sequence. ${ }^{15}$ The versatility of our method is further highlighted by the synthesis of $9,{ }^{15}$ accessing acrylamides that would be beyond reach otherwise with such a high regioselectivity via classical hydroamidation of alkynes posessing two different aromatic residues without steric bias. ${ }^{1,5,21}$

Scheme 2. Synthetic Applicability

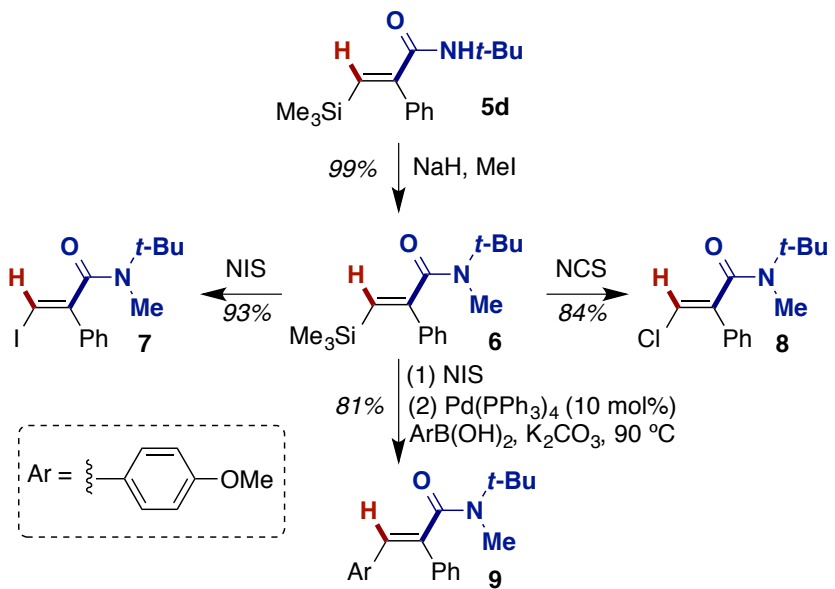

Next, we decided to perform deuterium-labeling experiments to gather evidence about the mechanism of our Ni-catalyzed hydroamidation protocol (Scheme 3, top pathway). As shown, 3a-D was prepared in high yields from either $\left(\mathrm{CD}_{3}\right)_{2} \mathrm{CHBr}$ or $\left(\mathrm{CH}_{3}\right)_{2} \mathrm{CDBr}$ with $75 \%$ and $15 \%$-D content, respectively, suggesting that a $\beta$-hydride elimination/migratory insertion might occur at some extent prior to alkyne binding. ${ }^{22}$ The stoichiomeric experiments with $\mathrm{Ni}(\mathbf{L} 4)_{2}$ are particularly illustrative (Scheme 3, bottom); ${ }^{23}$ specifically, we found that 3a was solely obtained in the presence of $i$ - $\mathrm{PrBr}$, thus ruling out an oxidative cyclization of $\mathrm{Ni}(0), \mathbf{1 a}$ and $\mathbf{2 a}$ en route to I. ${ }^{6}$ Although further studies are needed, we currently propose a pathway consisting of a hydrometalation with in situ generated $\mathrm{Ni}(\mathrm{II})$-hydride, single electron transfer (SET) mediated by $\mathrm{Mn}$ en route to a $\mathrm{Ni}(\mathrm{I})$ intermediate $^{24}$ followed by RNCO insertion ${ }^{25}$ and a final SET to recover the $\mathrm{Ni}(0)$ species. At present, we cannot rule out a RNCO insertion into vinyl-Ni(II) species or a comproportionation event to generate the corresponding $\mathrm{Ni}(\mathrm{I})$ intermediates, as a non-negligible yield of $\mathbf{3 a}$ was obtained in the absence of Mn (Scheme 3, bottom). ${ }^{26}$

Scheme 3. Mechanistic Experiments. 
Isotope-labelling studies

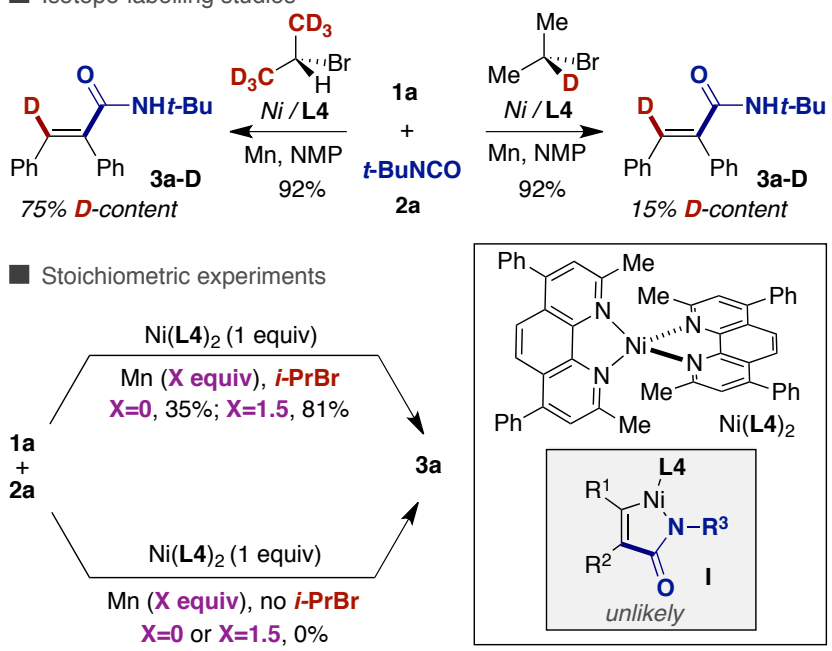

In summary, we have discovered a conceptually new and mild hydroamidation of alkynes with isocyanates by using in situ generated nickel hydrides from light bromoalkanes, turning parasitic $\beta$-hydride elimination into a strategic advantage. The method is characterized by its generality and excellent chemo- \& regioselectivity, suggesting that mechanistically distinct protocols could be initiated via $\beta$-hydride elimination. Further investigations along these lines are ongoing in our laboratories.

\section{ASSOCIATED CONTENT}

Supporting Information. Experimental procedures and spectral data. This material is available free of charge via the Internet at http://pubs.acs.org.

\section{AUTHOR INFORMATION}

\section{Corresponding Author}

* rmartinromo@iciq.es

\section{Author contributions}

* These authors contributed equally to this work

\section{Funding Sources}

No competing financial interests have been declared.

\section{ACKNOWLEDGMENT}

We thank ICIQ, the European Research Council (ERC277883), MINECO (CTQ2015-65496-R \& Severo Ochoa Excellence Accreditation 2014-2018, SEV-2013-0319) and Cellex Foundation for support. Johnson Matthey, Umicore and Nippon Chemical Industrial are acknowledged for a gift of metal \& ligand sources. E. Serrano thanks MINECO for a FPI fellowship. We sincerely thank E. Escudero and E. Martin for X-ray crystallographic data.

\section{REFERENCES}

(1) (a) Trost, B. M.; Ball, Z. T. Synthesis 2005, 6, 853. (b) Alonso, F.; Beletskaya, I. P.; Yus, M. Chem. Rev. 2004, 104, 3079. (c) Comprehensive Organic Synthesis, Vol. 8. Reduction; Trost, B.; Fleming, I., Eds.; Pergamon: Oxford, 1991.
(2) Trost, B. M. Chem, Eur. J. 1998, 4, 2405.

(3) (a) Ekici, Ö. D.; Li, Z. Z.; Campbell, A. J.; James, K. E.; Asgian, J. L.; Mikolajczyk, J.; Salvesen, G. S.; Ganesan, R.; Jelakovic, S.; Grütter, M. G.; Powers, J. C. J. Med. Chem. 2006, 49, 5728. (b) The Amide Linkage: Structural Significance in Chemistry, Biochemistry and Materials Science (Eds.: Greenberg, A.; Breneman, C. M.; Liebman, J. F.), Wiley-Interscience, New York, 2000.

(4) (a) Pace, V.; Monticelli, S.; de la Vega-Hernandez, K.; Castoldi, L. Org. Biomol. Chem. 2016, 14, 7848. (b) Ulrich, H. In Chemistry and Technology of Isocyanates, Ed.; John Wiley \& Sons, New York, 1996. (c) Ozaki, S. Chem. Rev. 1972, 72, 457.

(5) This technique will represent, conceptually aside, a powerful alternative to recent elegant hydrocarbamoylation techniques based on formamides that require rather specific substitution patterns, and in most instances, harsh conditions. See: (a) Fujihara, T.; Katafuchi, Y.; Iwai, T.; Terao, J.; Tsuji, Y. J. Am. Chem. Soc. 2010, 132, 2094. (b) Nakao, Y.; Idei, H.; Kanyiva, K. S.; Hiyama, T. J. Am. Chem. Soc. 2009, 131, 5070. (c) Kobayashi, Y.; Kamisaki, H.; Yanada, K.; Yanada, R.; Takemoto, Y. Tetrahedron Lett. 2005, 46, 7549. For aminocarbonylation techniques performed at $\mathrm{CO}$ pressures: (d) Park, J. H.; Kim, S. Y.; Kim, S. M.; Chung, Y. K. Org. Lett. 2007, 9, 2465. (e) Brennführer, A.; Neumann, H.; Beller, M. ChemCatChem 2009, 1, 28, and references therein.

(6) For reviews on cycloaddition techniques using isocyanates: (a) Thakur, A.; Louie, J. Acc. Chem. Res. 2015, 48, 2354. (b) Perreault, S.; Rovis, T. Chem. Soc. Rev. 2009, 38, 3149.

(7) For selected catalytic techniques not involving cycloaddition events: (a) Serrano, E.; Martin, R. Angew. Chem. Int. Ed. 2016, 55, 11207. (b) Correa, A.; Martin, R. J. Am. Chem. Soc. 2014, 136, 7253 (c) Hsieh, J.-C.; Cheng, C.-H. Chem. Commun. 2005, 4554. (e) Schleicher, K. D.; Jamison, T. F. Org. Lett. 2007, 9, 875.

(8) For selected seminal stoichiometric studies of metal complexes with isocyanates, see: (a) Hoberg, H.; Guhl, D. J. Organomet. Chem. 1990, 384, C43. (b) Hernandez, E.; Hoberg, H. J. Organomet. Chem. 1987, 328, 403. (c) Hoberg, H.; Summermann, K.; Milchereit, A. Angew. Chem., Int. Ed. Engl. 1985, 24, 325. (d) Villa, J.F.; Powell, H.B. Inorg. Chim. Acta 1979, 32, 199.

(9) Braunstein, P.; Nobel, D. Chem. Rev. 1989, 89, 1927.

(10) For selected reviews on metal hydrides: (a) Eberhardt, N. A.; Guan, H. Chem. Rev. 2016, 116, 8373. (b) Larionov, E.; Li, H.; Mazet, C. Chem. Commun. 2014, 50, 9816.

(11) For selected reviews: (a) Hu, X. Chem. Sci. 2011, 2, 1867. (b) Jana, R.; Pathak, T. P.; Sigman, M. S. Chem. Rev. 2011, 111, 1417. (c) Frisch, A. C.; Beller, M. Angew. Chem., Int. Ed. 2005, 44, 674.

(12) For elegant transfer hydrocyanations of $\pi$-systems initiated by $\beta$-hydride elimination: (a) Fang, X.; Yu, P.; Morandi, B. Science 2016, 351, 832. (b) Bhawal, B. N.; Morandi, B. ACS Catal. 2016, 6, 7528. (c) Fang, X.; Yu, P.; Cerai, G. P.; Morandi, B. Chem. Eur. -J. 2016, 22, 15629.

(13) For recent examples: (a) Börjesson, M.; Moragas, T.; Martin, R. J. Am. Chem. Soc. 2016, 138, 7504. (b) Moragas, T.; Gaydou, M.; Martin, R. Angew. Chem. Int. Ed. 2016, 55, 5053. (c) Wang, X.; Nakajima, M.; Martin, R. J. Am. Chem. Soc. 2015, 137, 8924. (d) Wang, X.; Liu, Y.; Martin, R. J. Am. Chem. Soc. 2015, 137, 6476. (e) Moragas, T.; Cornella, J.; Martin, R. J. Am. Chem. Soc. 2014, 136, 17702.

(14) Bailey, P. D.; Mills, T. J.; Pettecrew, R.; Price, R. A. In Comprehensive Organic Functional Groups Transformation II, Vol. 5, Eds.; A. R. Katritzky, R. J. K. Taylor, Elsevier, Oxford, 2005, pp. $201-294$.

(15) See the Supporting Information for details. 
(16) The mass balance accounts for semireduction of the alkyne.

(17) For reviews dealing with Ni-catalyzed cross-coupling reactions: (a) Tasker, S. Z.; Standley, E. A.; Jamison, T. F. Nature 2014, 509, 299. (b) Montgomery, J. Organonickel Chemistry. In Organometallics in Synthesis; Lipshutz, B. H., Ed.; Wiley; Hoboken, NJ, 2013; pp 319-428. (c) Rosen, B. M.; Quasdorf, K. W.; Wilson, D. A.; Zhang, N.; Resmerita, A.-M.; Garg, N. K. Percec, V. Chem. Rev. 2011, 111, 1346.

(18) (a) Hall, D. G. Boronic Acids-Preparation, Applications in Organic Synthesis and Medicine; Hall, D. G., Ed.; WileyVCH: Weinheim, Germany, 2005. (b) Coats, R. M.; Denmark, S.; Handbook of Reagents for Organic Synthesis. Reagents, Auxiliaries and Catalysts for $\mathrm{C}-\mathrm{C}$ Bond Formation; J. Wiley \& Sons, Inc., New York, 1999.

(19) For seminal studies in hyperconjugation with organic silanes: (a) Whitmore, F. C.; Sommer, L. H. J. Am. Chem. Soc. 1946, 68, 481. (b) Sommer, L. H.; Whitmore, F. C. J. Am. Chem. Soc. 1946, 68, 485.

(20) For selected reviews on Ni-catalyzed $\mathrm{C}-\mathrm{O}$ cleavage: (a) Tobisu, M.; Chatani, N. Acc. Chem. Res. 2015, 48, 1717. (b) Cornella, J.; Zarate, C.; Martin, R. Chem. Soc. Rev. 2014, 43, 8081. (c) Yamaguchi, J.; Muto, K.; Itami, K. Eur. J. Org. Chem. 2013, 19.

(21) In line with this notion, the hydroamidation of 1-methoxy-4(phenylethynyl)benzene led to 1:1 regioisomeric mixtures.
(22) 3a-D was obtained with complete D-incorporation when $\left(\mathrm{CD}_{3}\right) \mathrm{CDBr}$ was used as hydride source. Notably, no Dincorporation was observed when using $\mathbf{L} 4-\mathrm{d}_{6}$ (see ref. 15).

(23) Powers, D. C.; Anderson, B. L.; Nocera, D. G. J. Am. Chem. Soc. 2013, 135, $18876-18883$. For an improved protocol of $\mathrm{Ni}(0)$ (phenanthroline) $)_{2}$ complexes, see ref. $13 \mathrm{~b}$.

(24) For the formation of intermediate $\mathrm{Ni}(\mathrm{I})$ species generated from SET processes, see: (a) Laskowski, C. A.; Bungum, D. J.; Baldwin, S. M.; Del Ciello, S. A.; Iluc, V. M.; Hillhouse, G. L. J. Am. Chem. Soc. 2013, 135, 18272. (b) Breitenfeld, J.; Ruiz, J.; Wodrich, M. D.; Hu, X. J. Am. Chem. Soc. 2013, 135, 12004. (c) Biswas, S.; Weix, D. J. J. Am. Chem. Soc. 2013, 135, 16192. See also ref. 13.

(25) $\mathrm{Ni}(\mathrm{I})$ species have been shown to rapidly react with heterocumulenes other than RNCO, see: Menges, F. S.; Craig, S. M.; Tçtsch, N.; Bloomfield, A.; Ghosh, S.; Krüger, H. -J.; Johnson, M. A. Angew. Chem. Int. Ed. 2016, 55, 1282.

(26) For selected comproportionation events en route to $\mathrm{Ni}(\mathrm{I})$ species, see: (a) Cornella, J.; Gomez-Bengoa, E.; Martin, R. J. Am. Chem. Soc. 2013, 135, 1997. (b) Velian, A.; Lin, S.; Miller, J. M.; Day, M. W.; Agapie, T. J. Am. Chem. Soc. 2010, 132, 6296. (d) Jones, G. D.; Martin, J. L.; McFarland, C.; Allen, O. R.; Hall, R. E.; Haley, A. D.; Brandon, R. J.; Konovalova, T.; Desrochers, P. J.; Pulay, P.; Vicic, D. A. J. Am. Chem. Soc. 2006, 128, 13175.

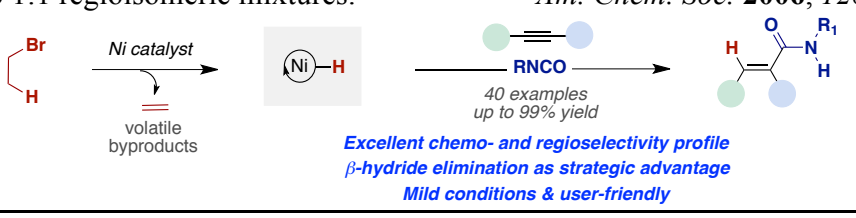

